\title{
Identification of 5 novel genes methylated in breast and other epithelial cancers
}

\author{
Victoria K Hill', Luke B Hesson ${ }^{1,2}$, Temuujin Dansranjavin ${ }^{3}$, Ashraf Dallol ${ }^{1}$, Ivan Bieche ${ }^{4}$, Sophie Vacher ${ }^{4}$, \\ Stella Tommasi ${ }^{5}$, Timothy Dobbins ${ }^{2}$, Dean Gentle ${ }^{1}$, David Euhus ${ }^{6}$, Cheryl Lewis ${ }^{6}$, Reinhard Dammann ${ }^{3}$, \\ Robyn L Ward ${ }^{2}$, John Minna ${ }^{7}$, Eammon R Maher', Gerd P Pfeifer ${ }^{5}$, Farida Latif ${ }^{1 *}$
}

\begin{abstract}
Background: There are several high throughput approaches to identify methylated genes in cancer. We utilized one such recently developed approach, MIRA (methylated-CpG island recovery assay) combined with CpG island arrays to identify novel genes that are epigenetically inactivated in breast cancer.

Results: Using this approach we identified numerous CpG islands that demonstrated aberrant DNA methylation in breast cancer cell lines. Using a combination of COBRA and sequencing of bisulphite modified DNA, we confirmed 5 novel genes frequently methylated in breast tumours; EMILIN2, SALL1, DBC1, FBLN2 and CIDE-A. Methylation frequencies ranged from between $25 \%$ and $63 \%$ in primary breast tumours, whilst matched normal breast tissue DNA was either unmethylated or demonstrated a much lower frequency of methylation compared to malignant breast tissue DNA. Furthermore expression of the above 5 genes was shown to be restored following treatment with a demethylating agent in methylated breast cancer cell lines. We have expanded this analysis across three other common epithelial cancers (lung, colorectal, prostate). We demonstrate that the above genes show varying levels of methylation in these cancers. Lastly and most importantly methylation of EMILIN2 was associated with poorer clinical outcome in breast cancer and was strongly associated with estrogen receptor as well as progesterone receptor positive breast cancers.

Conclusion: The combination of the MIRA assay with $\mathrm{CpG}$ island arrays is a very useful technique for identifying epigenetically inactivated genes in cancer genomes and can provide molecular markers for early cancer diagnosis, prognosis and epigenetic therapy.
\end{abstract}

\section{Background}

In most Western countries breast cancer is a leading cause of cancer related deaths in women. Breast cancer accounts for over one million of the estimated 10 million cancers that are diagnosed globally each year in both males and females and claimed about 375,000 deaths in the year 2000 [1]. The use of screening mammography and MRI has led to a decline in breast cancer-related mortality. But these screening procedures can also lead to overdiagnosis and false positive cases leading to unnecessary treatment. Therefore there is a critical need to develop molecular biomarkers that can detect early stage disease so that treatment can begin promptly.

\footnotetext{
* Correspondence: f.latif@bham.ac.uk
'Department of Medical and Molecular Genetics, School of Clinical and

* Correspondence: f.latif@bham.ac.uk
'Department of Medical and Molecular Genetics, School of Clinical and Experimental Medicine, College of Medical and Dental Sciences, University of Birmingham, Birmingham B15 2TT, UK
}

(c) 2010 Hill et al; licensee BioMed Central Ltd. This is an Open Access article distributed under the terms of the Creative Commons Attribution License (http://creativecommons.org/licenses/by/2.0), which permits unrestricted use, distribution, and reproduction in any medium, provided the original work is properly cited.

Genetic as well as epigenetic changes play crucial roles in tumour development and progression. Alterations in DNA methylation include both genome-wide hypomethylation and hypermethylation events. Promoter hypermethylation at specific gene loci is a major mechanism of epigenetic inactivation in cancer cells leading to gene silencing. A recent genome-wide study in breast and colon cancer led to identification of tumour suppressor genes that are inactivated by both genetic and epigenetic events and importantly reduced expression of a subset of these genes correlated with poor clinical outcome [2]. Although the list of hypermethylated genes in breast cancer is growing, only a few show promise as biomarkers for early detection and risk assessment $[3,4]$. We and others identified RASSF $1 A$ as one of the most highly methylated genes in many cancer types including breast cancer $[5,6]$. Identification of more genes of this type 
would facilitate the development of sensitive molecular markers across multiple malignancies.

In the present study we employed a genome-wide approach to identify methylated genes in breast cancer and further investigated these genes in other common epithelial cancers. For the high throughput genomewide DNA methylation approach we utilized a very sensitive assay recently developed in our laboratory (Gerd Pfeifer lab). The methylated-CpG island recovery assay (MIRA) is based on the high affinity of the MBD2/ MBD3L1 complex for methylated DNA and allows one to detect cell type-dependent differences in DNA methylation when used in combination with $\mathrm{CpG}$ island arrays $[7,8]$.

\section{Results}

\section{Genome-wide approach identifies methylated genes in} breast cancer

We used the MIRA assay in combination with genomewide $\mathrm{CpG}$ island arrays containing 27,800 loci to identify methylated $\mathrm{CpG}$ islands in 5 breast cancer cell lines (HCC1806, HCC1419, HCC1143, HCC1937, HCC1395) relative to normal human mammary epithelial cells (NHMEC) [7,8]. A primary selection based on probes showing $>5$ fold enrichment of the methylated fraction in breast cancer cell lines versus NHMEC cell line DNA across 3 or more cell lines or a more stringent selection with probes scoring greater than 10 in 4 or more cell lines yielded a large number of loci showing methylation across breast cancer cell lines (see additional 1). These included genes/loci previously reported to be methylated in breast cancer (for example SIM1, PAX6, DLX4, $R U N X 3)$. In order to reduce the list to manageable numbers we carried out bioinformatic analyses to gather information on the expression of target genes in breast tissue, confirmation of the presence of a CpG island within the likely promoter region of target genes and functional annotation to determine likely roles in tumourigenesis, see materials and methods for more information. This led to a selection of 32 novel genes for further analysis (Figure 1, see additional file 2) in a stepwise fashion including the following stages:

1. Methylation analysis in breast cancer cell lines and normal control breast tissue DNA.

2. Methylation analysis in a panel of breast tumours $(\mathrm{n}=40)$

3. Gene expression analysis before and after 5-aza$\mathrm{dC}$ treatment

4. Methylation analysis in an independent cohort of paired normal/tumour breast DNA panel $(\mathrm{n}=20)$

5. Expand methylation analysis to include lung, colorectal and prostate cancer, for the genes showing tumour-specific methylation in breast cancer.

\section{Methylation analysis in breast tumours and breast} tumour cell lines

We used COBRA digest to ascertain the methylation levels across a panel of 9 breast cancer cell lines (including the 5 lines used for MIRA) in CpG island regions upstream of the transcription start site. We confirmed frequent methylation (>30\%) for 16 loci in breast cancer cell lines. These loci were unmethylated in DNA from normal/control breast. Sixteen loci either showed low or no methylation in the panel of breast cancer cell lines or were equally methylated in normal control breast DNA in the region analysed by our COBRA primers and were removed from further analysis (Figure 1). The remaining 16 positive genes demonstrating frequent methylation in breast cancer cell lines were analysed further by COBRA digest in a panel of primary breast tumours $(n=40)$. Nine (CIDE-A, COMP, DBC1, EMILIN2, EPSTI1, FBLN2, SALL1, SESN3, SIM2) of these genes $(56 \%)$ demonstrated frequent methylation in primary breast tumours (frequency ranging from 26-63\%) (Figure 1, 2, 3, 4, 5, 6)

\section{Expression analysis in breast tumour cell lines and normal breast}

The above nine frequently methylated genes were shown to be expressed in normal breast tissue (Figure 2, 3, 4, 5, $6)$. In order to determine the role of methylation in gene silencing, we treated breast cancer cell lines with the demethylating agent 5-aza-dC. Eight (CIDE-A, COMP, DBC1, EMILIN2, EPSTI1, FBLN2, SALL1, SIM2) of the above nine genes showed re-expression after treatment of the methylated cell lines with 5aza-dC (Figure 2, 3, 4, $5,6)$. Hence methylation suppressed gene expression, whilst SESN3 showed no change in expression before and after treatment in both methylated and unmethylated cell lines. SESN3 was therefore not considered for further analysis.

\section{Methylation analysis in paired normal/ tumour breast cases}

To determine if methylation of the eight remaining genes was cancer-specific (i.e. tumour acquired), we analysed an independent set of paired normal/tumour breast DNA samples $(\mathrm{n}=20)$. Five genes $(62.5 \%)$ demonstrated tumour acquired methylation (EMILIN2, $S A L L 1, D B C 1, F B L N 2$ and $C I D E-A$ ) (Table 1, Figures 2, $3,4,5,6)$, whilst the remaining 3 (COMP, EPSTI1, SIM2) showed equal methylation in the corresponding normal breast tissue DNA. The COBRA results for these 5 genes were confirmed by cloning and sequencing of bisulphite modified DNA in primary breast tumours (Figures 2, 3, 4, 5, 6). In majority of the breast tumour samples we also detected the unmethylated product. This is likely to be due to the contamination from 


\section{A}

\section{CoBRA analysis of $\mathbf{3 2}$ genes in cell lines}

\begin{tabular}{|c|c|}
\hline \multicolumn{2}{|c|}{ CELL LINES } \\
\hline ABT1 & $0 / 5(0 \%)$ \\
\hline BARHL2 & $2 / 8(25 \%)$ \\
\hline BUB3 & $0 / 9(0 \%)$ \\
\hline CCNJ & $0 / 6(0 \%)$ \\
\hline CD44 & $3 / 6(50 \%)$ \\
\hline CDH24 & $0 / 9(0 \%)$ \\
\hline CENPJ & $0 / 9(0 \%)$ \\
\hline CIDE-A & $7 / 8(86 \%)$ \\
\hline COMP & $4 / 6(67 \%)$ \\
\hline DBC1 & $2 / 6(33 \%)$ \\
\hline DDEF2 & $0 / 6(0 \%)$ \\
\hline DLGAP1 & $5 / 5(100 \%)$ \\
\hline EMILIN2 & $5 / 9(56 \%)$ \\
\hline EPSTI1 & $5 / 6(83 \%)$ \\
\hline FBLN2 & $3 / 5(60 \%)$ \\
\hline FOXF2 & $6 / 9(67 \%)$ \\
\hline FOXQ1 & $1 / 6(17 \%)$ \\
\hline GSC & $3 / 9(33 \%)$ \\
\hline KLF11 & $0 / 9(0 \%)$ \\
\hline KLF13 & $0 / 6(0 \%)$ \\
\hline LYPD5 & $3 / 6(50 \%)$ \\
\hline MAD1L1 & $0 / 6(0 \%)$ \\
\hline NRXN2 & $2 / 6(33 \%)$ \\
\hline ONECUT1 & $0 / 9(0 \%)$ \\
\hline PAX9 & $4 / 5(80 \%)$ \\
\hline PHF2 & $0 / 6(0 \%)$ \\
\hline POU4F1 & $6 / 8(75 \%)$ \\
\hline SALL1 & $4 / 6(67 \%)$ \\
\hline SALL3 & $3 / 4(75 \%)$ \\
\hline SESN3 & $6 / 6(100 \%)$ \\
\hline SIM2 & $7 / 7(100 \%)$ \\
\hline TP53INP1 & $3 / 6(50 \%)$ \\
\hline
\end{tabular}

B

\section{CoBRA analysis of 16 genes} in primary tumours

\begin{tabular}{|c|c|}
\hline \multicolumn{2}{|c}{ PRIMARY TUMOURS } \\
\hline CD44 & $1 / 24(4 \%)$ \\
\hline CIDE-A & $21 / 40(53 \%)$ \\
\hline COMP & $20 / 33(61 \%)$ \\
\hline DBC1 & $8 / 31(26 \%)$ \\
\hline EMILIN2 & $16 / 36(44 \%)$ \\
\hline EPSTI1 & $13 / 36(36 \%)$ \\
\hline FBLN2 & $13 / 38(34 \%)$ \\
\hline FOXF2 & $5 / 35(14 \%)$ \\
\hline GSC & $1 / 40(3 \%)$ \\
\hline NRXN2 & $0 / 12(0 \%)$ \\
\hline PAX9 & $8 / 39(21 \%)$ \\
\hline POU4F1 & $4 / 27(15 \%)$ \\
\hline SALL1 & $25 / 40(63 \%)$ \\
\hline SESN3 & $7 / 10(70 \%)$ \\
\hline SIM2 & $24 / 29(83 \%)$ \\
\hline TP53INP1 & $0 / 18(0 \%)$ \\
\hline
\end{tabular}

Figure 1 Stepwise analysis of $\mathbf{3 2}$ selected genes in breast cancer. (A) Cell line analysis confirmed frequent methylation (>30\% of samples) in cancer cell lines but not normal/control breast tissue in 16 genes (highlighted in white), which were selected for further analysis. Thirteen genes (highlighted in light grey) did not show methylation in the region analysed by our CoBRA primers and were removed from further analysis. Three genes (highlighted in dark grey) showed frequent methylation in cancer cell lines but also normal breast tissue and were removed from further analysis. (B) Analysis of the 16 genes found to be frequently methylated in cell lines were analysed in primary breast cancer patient samples. Frequent methylation (>25\% of samples) was observed in nine of these genes (highlighted in white) and were carried forward for expression analysis.

normal cells, since none of the tumours were microdissected and due to the heterogeneous nature of the primary tumour samples.

\section{Methylation analysis in other epithelial cancers}

To explore whether the above 5 genes showing tumour-specific methylation in breast cancer were methylated in other epithelial cancers besides breast, we analysed a panel of cancer cell lines corresponding to three common epithelial cancers (lung, colorectal and prostate). Lung tumour cell lines (NSCLC) demonstrated frequent methylation of CIDE-A, EMILN2, $F B L N 2$ and $S A L L 1 . D B C 1$ methylation in lung cancer has been reported previously hence it was not analysed in this study [9]. Colorectal tumour lines showed frequent methylation of all 5 genes, whilst prostate 


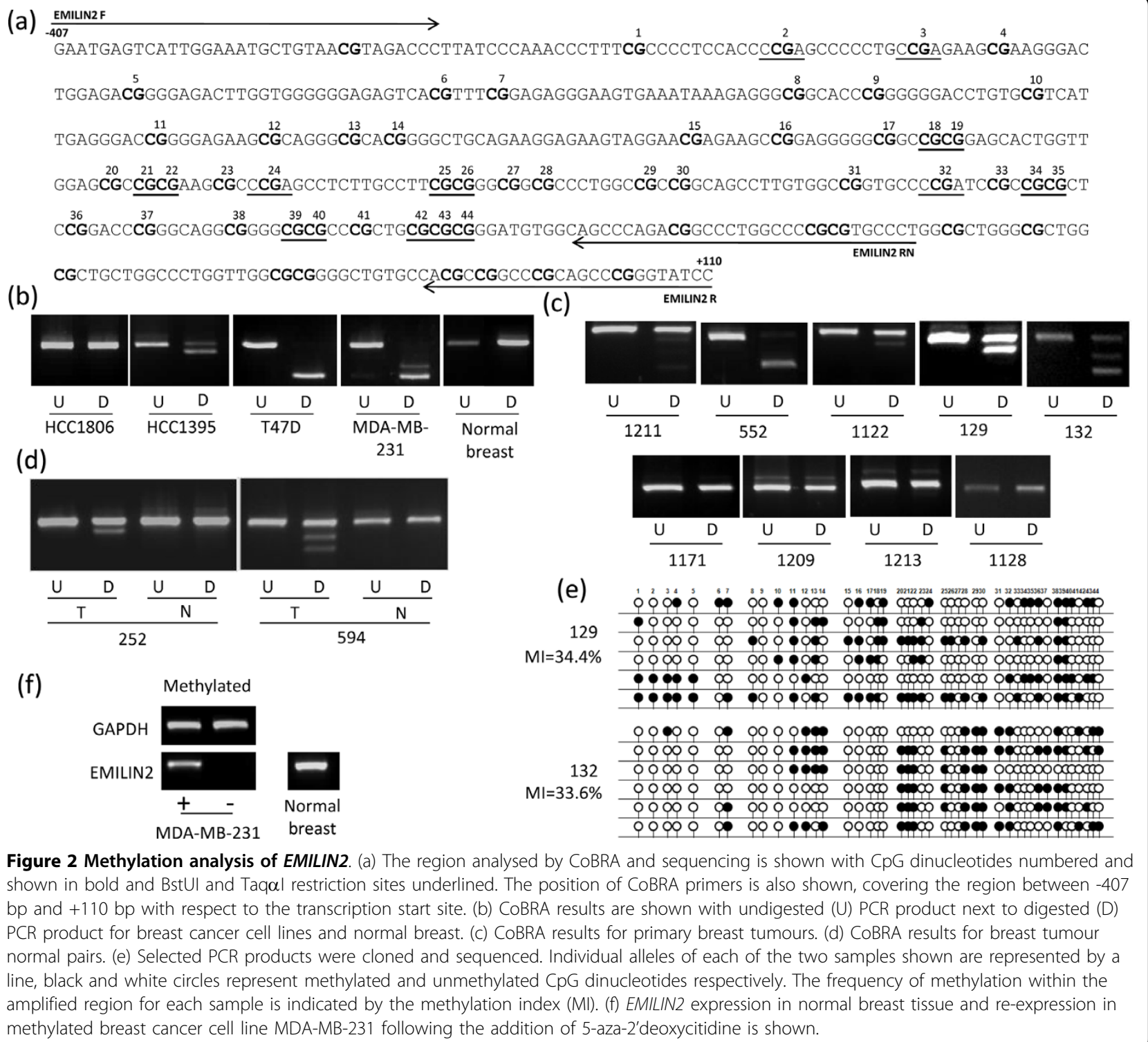

tumour lines demonstrated frequent methylation of CIDE-A, DBC1, EMILIN2, SALL1 and less frequent methylation for FBLN2 (Table 2).

To demonstrate tumour specific methylation in other epithelial cancers

The above genes were further analyzed in primary tumours for the tumour types that demonstrated frequent methylation in the corresponding tumour cell lines. Where applicable N/T paired DNA was analysed (Table 2).

EMILIN2 was methylated in 33\% colorectal carcinomas $(\mathrm{CRC})$ and in $32 \%$ adenomas, whilst only $1.2 \%$ of corresponding normal tissues demonstrated any methylation. Methylation was confirmed using cloning and sequencing of bisulphite modified DNA (Figure 7).
Whilst NSCLC and prostate tumours were either unmethylated or showed very low level frequency of methylation in both tumours and corresponding normals (Table 2).

SALL1 was methylated in $83 \%$ of CRC and in $89 \%$ of adenomas, whilst methylation frequency in corresponding normals was much less (38\%). SALL1 demonstrated similar frequencies of methylation in tumour and matched normal samples for both NSCLC and prostate tumours (Table 2).

$D B C 1$ was frequently methylated in CRC and prostate cancer cell lines (we did not analyse NSCLC since $D B C 1$ is already known to be methylated in this cancer). In CRC and adenomas the methylation frequency was $100 \%$ but it was not cancer specific, all corresponding normals were also methylated. This could indicate that 
(a)

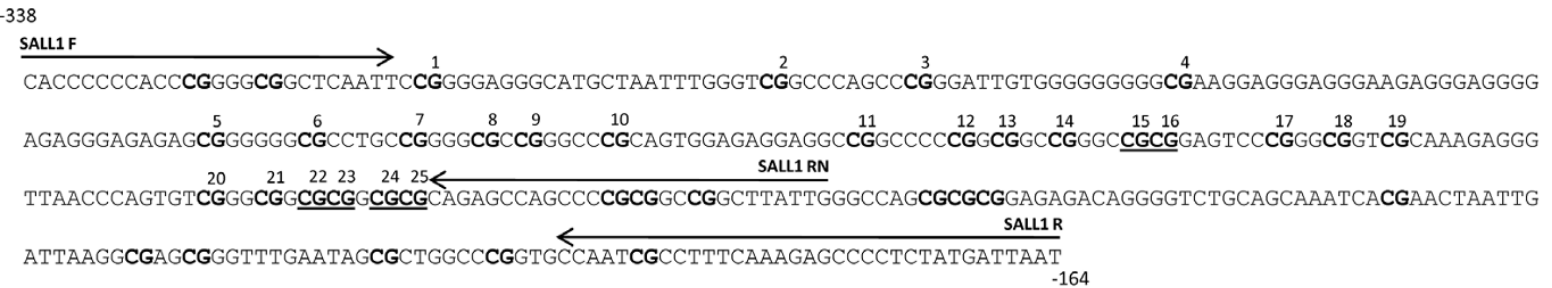

(b)
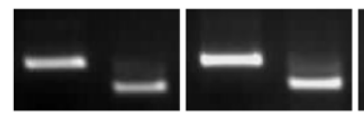

U D HCC1419

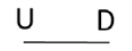
HCC1937
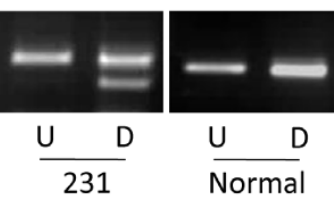

(c)

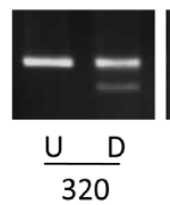

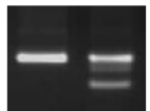

$\frac{U \quad D}{1122}$

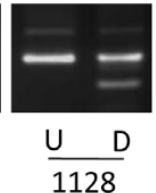

(d)
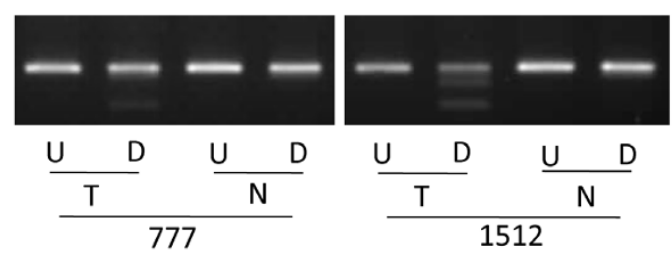

(e)

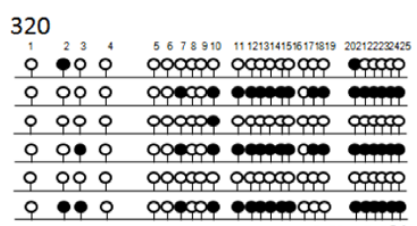

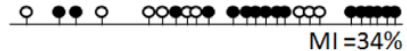

409

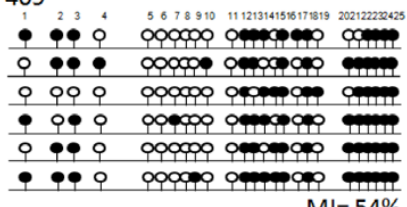

1122

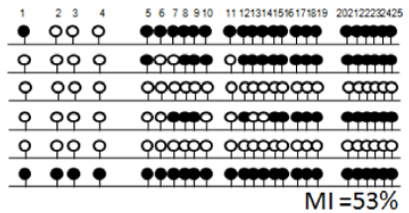

1128

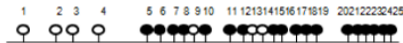

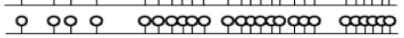
ㅇ 90 ㅇ

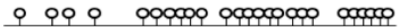

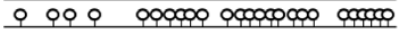

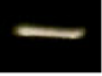

$\mathrm{Ml}=54 \%$

Figure 3 Methylation analysis of SALL1. (a) The region analysed by COBRA and sequencing is shown with CpG dinucleotides numbered and shown in bold and BstUI restriction sites underlined. The position of CoBRA primers is also shown, covering the region between - 338 bp and -164 bp with respect to the transcription start site. (b) CoBRA results are shown with undigested (U) PCR product next to digested (D) PCR product for breast cancer cell lines and normal breast. (c) CoBRA results for primary breast tumours. (d) CoBRA results for breast tumour normal pairs. (e) Selected PCR products were cloned and sequenced. Individual alleles of each of the four samples shown are represented by a line, black and white circles represent methylated and unmethylated $\mathrm{CpG}$ dinucleotides respectively. The frequency of methylation within the amplified region for each sample is indicated by the methylation index (MI). (f) SALL1 expression in normal breast tissue and upregulation in methylated breast cancer cell line HCC1937 following the addition of 5-aza-2'deoxycitidine is shown.

$D B C 1$ undergoes tissue-specific methylation in certain tissues but not in others. Whilst weak methylation was seen in 1 out of 14 prostate tumours and 2 out of 4 normals (Table 2 ).

FBLN2 demonstrated tumour specific methylation in prostate tumours (36\%) and was unmethylated in lung tumours. FBLN2 similar to $D B C 1$ demonstrated very high frequency of methylation in colorectal tumours, adenomas and corresponding normal samples (Table 2).

$C I D E-A$ was found to be methylated in $7 / 8$ analysed primary CRC tumours and in all adenomas and corresponding normals. It has been recently demonstrated that $C I D E-A$ expression is epigenetically controlled in certain tissue and cell types [10], which when taken in consideration with our methylation analysis, suggests that normal colorectal tissue does not express CIDE-A.
Whilst a similar percentage of methylation frequency was seen in prostate tumours and corresponding normals ( $21 \%$ and $25 \%$ respectively). $C I D E-A$ was methylated in 1/16 NSCLC and 0/16 matched normals (Table 2).

\section{Methylation status and clinicopathological parameters}

The most interesting finding in the breast cancer cohort was that the methylation of EMILIN2 was associated with relapse $(\mathrm{P}=0.031)$, presence of lymph node metastases $(\mathrm{P}=0.047)$, with $\mathrm{ER}$ and $\mathrm{PR}$ positive tumours $(\mathrm{P}=$ $0.0009 ; 0.0082$ respectively) and poor relapse free survival $(\mathrm{P}=0.041)$ (Figure 8$)$. $C I D E-A$ methylation was associated with ER positive tumours $(\mathrm{P}=0.016)$, whilst FBLN2 methylation was associated with PR positive tumours $(\mathrm{P}=0.013)$. 


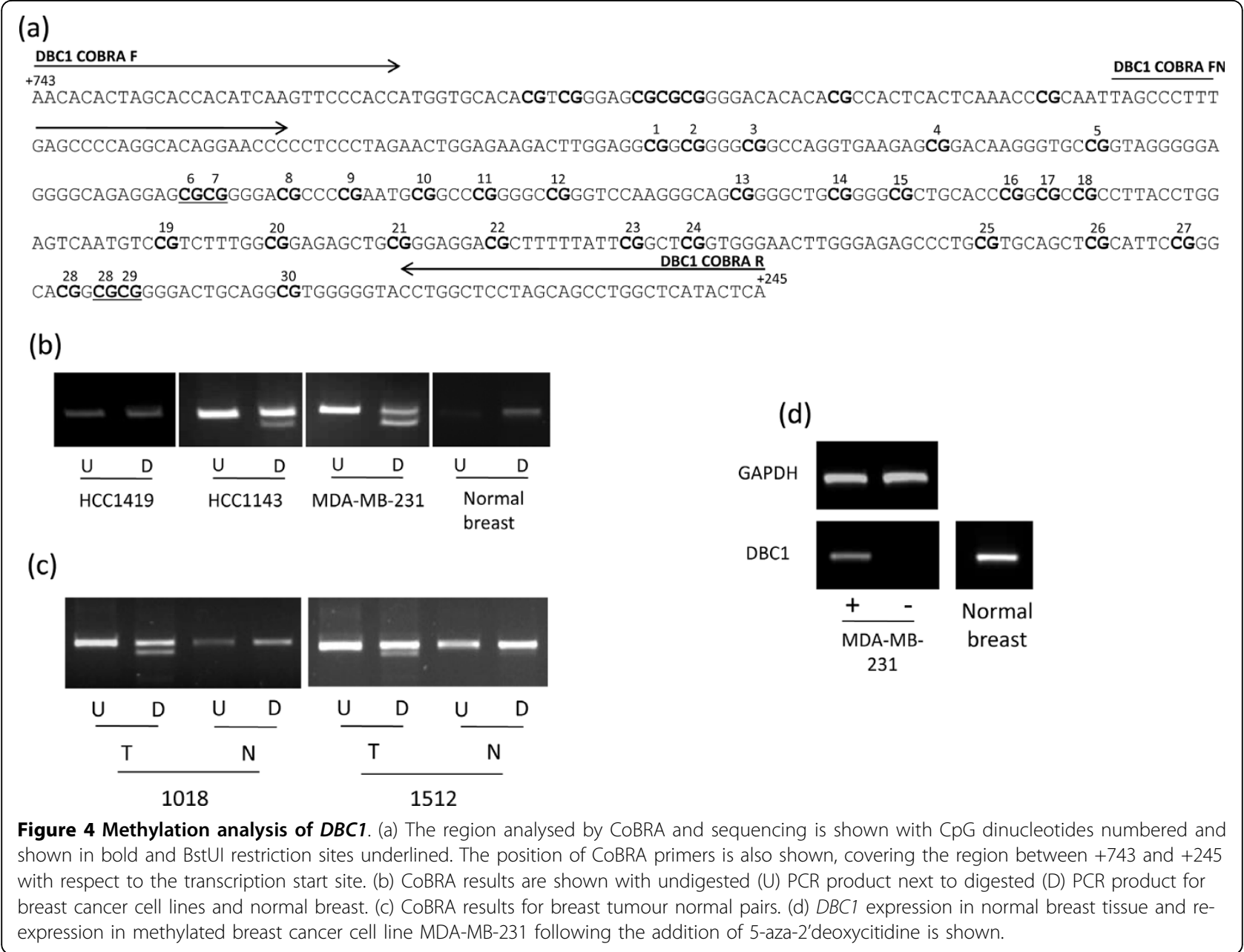

\section{Expression analysis of EMILIN2 in breast tumours}

EMILIN2 appears to be the most interesting gene due to the association between its methylation status and clinical-pathological features including survival. To confirm that the methylation of EMILIN2 is functionally relevant, we determined EMILIN2 expression in a subset of primary breast tumours (good quality RNA was available for these samples) using quantitative real-time RT-PCR. Expression analysis revealed that the breast tumours with EMILIN2 methylation showed lower levels of EMILIN2 expression compared to unmethylated tumours (Figure 9).

\section{Discussion}

Using a high throughput genome-wide approach we have identified 5 genes showing frequent tumour acquired methylation in breast cancer. To the best of our knowledge methylation of EMILIN2, SALL1, DBC1, $F B L N 2$, or $C I D E-A$ has not been reported previously in breast cancer. Furthermore we demonstrate that the methylation is cancer specific and leads to gene silencing. In addition we found that EMILIN2, FBLN2 and $S A L L 1$ were also frequently methylated in other common epithelial cancers, EMILIN2 and SALL1 in colorectal cancer and $F B L N 2$ in prostate cancer. To the best of our knowledge EMILIN2 and CIDE-A methylation in primary tumours has not been previously reported, $S A L L 1$ and FBLN2 methylation has been previously reported in acute lymphocytic leukemia $[11,12]$ and $D B C 1$ methylation has been reported in NSCLC, bladder cancer, oral cancer and in leukaemia [9,13-15].

EMILIN2 belongs to a family of extracellular matrix (ECM) glycoproteins containing an EMI domain at the $\mathrm{N}$-terminus and a $\mathrm{gC} 1 \mathrm{q}$ domain at the $\mathrm{C}$-terminus. EMILIN2 has been shown to suppress growth of cancer cells [16] and triggers apoptosis in cancer cells via the extrinsic apoptosis pathway following EMILIN2 binding to the trail receptors DR4 and DR5.

CIDE-A belongs to a novel family of cell death inducing DFF45 (DNA fragmentation factor-45) like effector proteins. In humans there are three family members (CIDE-A, CIDE-B, CIDE-C). In cell lines overexpression 


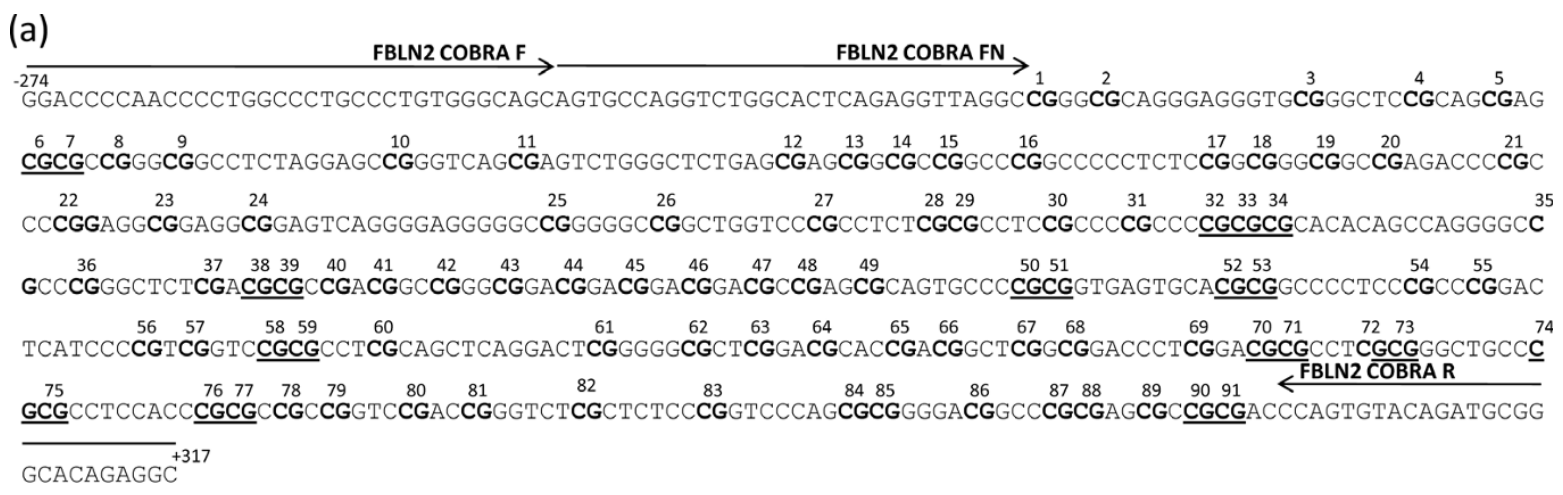

(b)

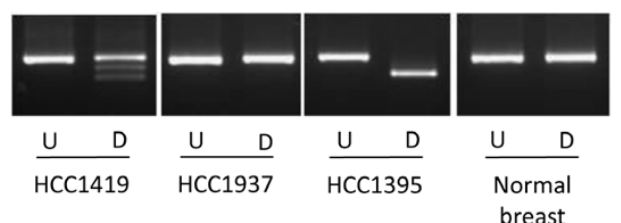

(d)

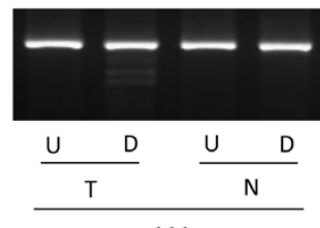

111

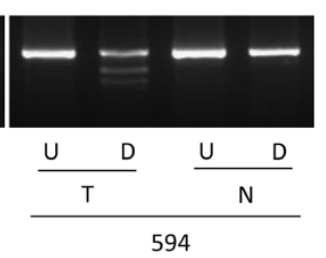

(c)

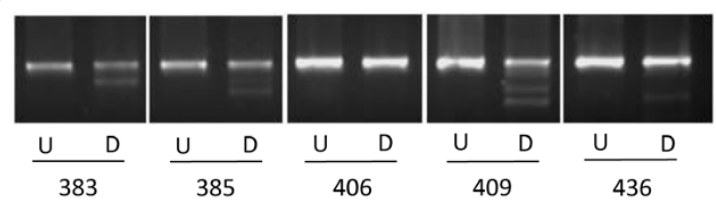

(e)

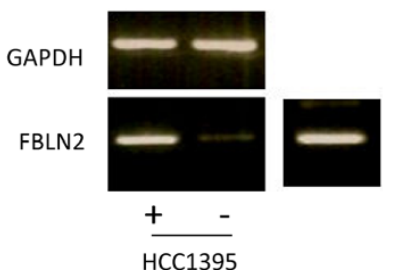

Figure 5 Methylation analysis of FBLN2. (a) The region analysed by CoBRA and sequencing is shown with CpG dinucleotides numbered and shown in bold and BstUI restriction sites underlined. The position of CoBRA primers is also shown, covering the region between -274 and +317 with respect to the transcription start site. (b) CoBRA results are shown with undigested (U) PCR product next to digested (D) PCR product for breast cancer cell lines and normal breast. (c) CoBRA results for primary breast tumours. (d) CoBRA results for breast tumour normal pairs. (e) FBLN2 expression in normal breast tissue and upregulation in methylated breast cancer cell line HCC1395 following the addition of 5-aza2'deoxycitidine is shown.

of CIDE-A leads to caspase-independent cell death associated with DNA fragmentation [17]. In addition, mice lacking functional Cidea have higher metablic rates and lipolysis in the brown adipose tissue as well as being resistant to diet-induced obesity and diabetes as compared to their wildtype littermates [18]. A recent report indicates that $\mathrm{CpG}$ methylation plays a critical role in determining tissue and cell specific expression of the CIDE-A gene [10].

FBLN2 encodes for an extracelluar matrix protein, belonging to a 6 member family of fibulins. FBLN2 binds various extracellular ligands and calcium. It acts as a scaffold protein in the ECM by binding to a variety of ligands including type IV collagen, fibronectin, fibrinogen, fibrillin, laminins, aggrecan and versican. It was recently shown to be downregulated in breast cancer cell lines and primary breast tumours. Reintroduction of FBLN2 into breast cancer cell lines lacking FBLN2 reduced cell motility and invasion in vitro but had no effect on cell growth and adhesion. Whilst, loss of
FBLN2 expression increased cell migration and invasion [19]. Recently another member of the Fibulin gene family, FBLN3 (EFEMP1) was shown to be frequently methylated in breast tumours [20].

DBC1 (deleted in bladder cancer 1) was identified from a common region of loss of heterozygosity at 9q32-q33 in bladder cancer. DBC1 has been shown to be frequently methylated in bladder cancer, NSCLC, oral cancer and acute lymphocytic leukemia [9,13-15]. Exogenous expression of DBC1 in NSCLC and in bladder cancer cell lines lacking DBC1 expression inhibited cell growth $[9,21]$. It has also been demonstrated that DBC1 plays a role in cell cycle control [21].

SALL1 is a human homologue of the Drosophila region-specific homeotic gene spalt (sal). The SALL1 gene product is a zinc finger protein thought to act as a transcription factor and maybe part of the NuRD histone deacetylase complex. Mice lacking Sall1 die in the perinatal period from kidney agenesis [22]. TownesBrocks syndrome affecting limb, ear, kidney and heart 
(a)

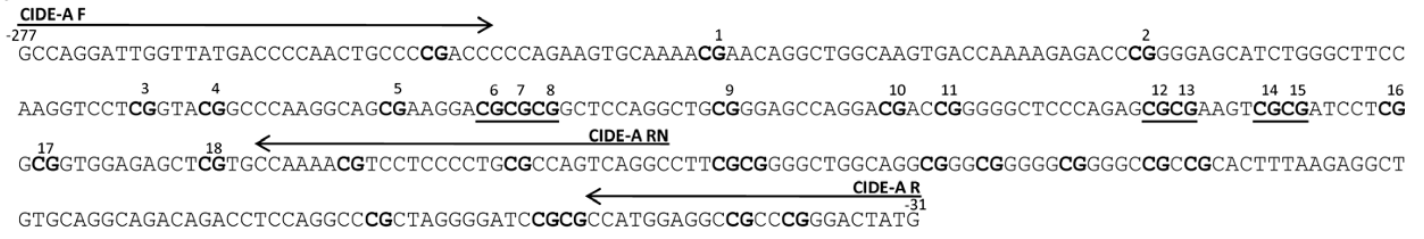

(b)

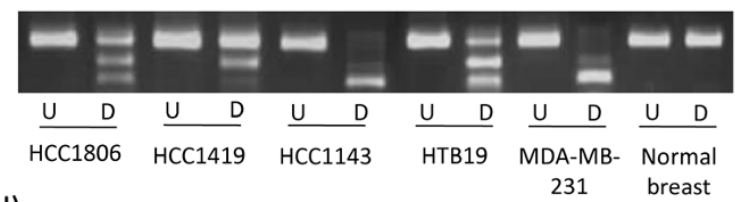

(c)

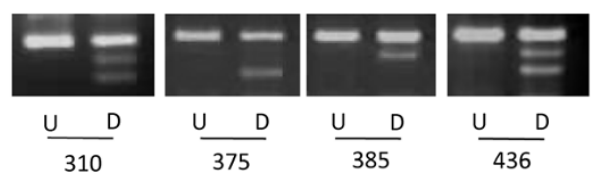

(d)

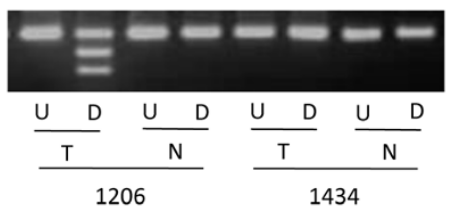

(f)

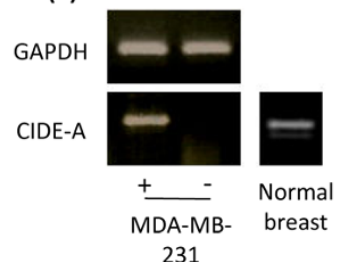

(e)
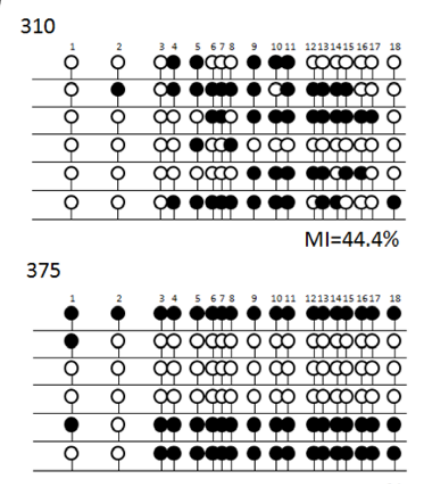

$\mathrm{Ml}=48.1 \%$

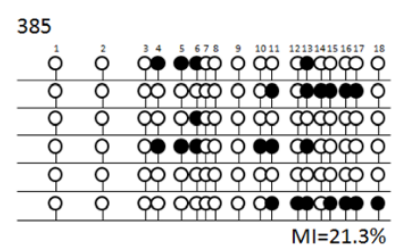

436

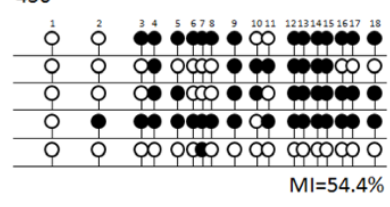

Figure 6 Methylation analysis of CIDE-A. (a) The region analysed by CoBRA and sequencing is shown with CpG dinucleotides numbered and shown in bold and BstUI restriction sites underlined. The positions of CoBRA primers are also shown, covering the region between -277 and -31 with respect to the transcription start site. (b) CoBRA results are shown with undigested (U) PCR product next to digested (D) PCR product for breast cancer cell lines and normal breast. (c) CoBRA results for primary breast tumours. (d) CoBRA results for breast tumour normal pairs. (e) Selected PCR products were cloned and sequenced. Individual alleles of each of the four samples shown are represented by a line, black and white circles represent methylated and unmethylated CpG dinucleotides respectively. The frequency of methylation within the amplified region for each sample is indicated by the methylation index (MI). (f) CIDE-A expression in normal breast tissue and re-expression in methylated breast cancer cell line MBA-MD-231 following the addition of 5-aza-2'deoxycitidine is shown.

Table 1 Methylation frequencies in breast cancer

\begin{tabular}{llllll}
\hline & CIDE-A & DBC1 & EMILIN2 & FBLN2 & SALL1 \\
\hline Cell lines & $7 / 8(88 \%)$ & $2 / 6(34 \%)$ & $5 / 9(56 \%)$ & $3 / 5(60 \%)$ & $4 / 6(67 \%)$ \\
Tumours & $21 / 40(53 \%)$ & $8 / 31(26 \%)$ & $16 / 36(45 \%)$ & $13 / 38(34 \%)$ & $25 / 40(63 \%)$ \\
Matched pairs & $7 / 15(47 \%)$ & $4 / 16(25 \%)$ & $4 / 10(40 \%)$ & $6 / 19(32 \%)$ & $10 / 20(50 \%)^{*}$ \\
\hline
\end{tabular}

Frequencies of methylation in breast cancer cell lines, primary breast tumours and matched breast tumour/normal pair samples are shown for EMILIN2, SALL1, $D B C 1, F B L N 2$ and CIDE-A. All tumour/normal pair figures represent the number of pairs that show tumour specific methylation, $(*)$ indicates that one of these pairs also showed methylation in the corresponding normal.

development is caused by defects in the SALL1 gene [23]. SALL1 was recently demonstrated to be hypermethylated in acute lymphocytic leukemia [11].

It has been demonstrated that methylated genes often reside in regions of chromosomal loss [2]. SALL1 resides at 16q12.1- a region demonstrated to undergo loss of heterozygosity $(\mathrm{LOH})$ in breast, prostate, ovarian cancer and in retinoblastoma [24,25]. EMILIN2 is located at 18 p11.3 in a region showing LOH in NSCLC, CRC and breast cancer [26]. FBLN2 is located at 3p25.1 in a region well documented for allelic loss in renal cell carcinoma and breast cancer $[27,28]$. CIDE- $A$ is located at 18 p11.2 in a region showing allelic loss in esophageal squamous cell carcinoma [29] and DBC1 was identified from a region of frequent loss of hetrozygosity at 9q3233 in bladder cancer [30].

Breast cancer is a hormone dependent cancer. In patients with breast cancer estrogen receptor (ER) status is an important treatment and prognostic factor. The response of breast cancer patients to endocrine therapy 
Table 2 Methylation frequencies in lung, colorectal and prostate cancers.

\begin{tabular}{llllll}
\hline & CIDE-A & DBC1 & EMILIN2 & FBLN2 & SALL1 \\
\hline Lung tumour lines & $11 / 15$ & not done & $4 / 10$ & $7 / 9$ & $4 / 13$ \\
Lung tumours & $1 / 16$ & not done & $1 / 13$ & $0 / 11$ & $4 / 16$ \\
Lung benign & $0 / 16$ & not done & $1 / 17$ & $0 / 10$ & $3 / 17$ \\
& & & & & \\
Colorectal tumour lines & $8 / 8$ & $8 / 8$ & $4 / 5$ & $4 / 4$ & $6 / 6$ \\
Colorectal tumours & $7 / 8$ & $8 / 8$ & $19 / 57$ & $54 / 58$ & $44 / 53$ \\
Colorectal adenomas & $7 / 7$ & $8 / 8$ & $7 / 22$ & $23 / 23$ & $17 / 19$ \\
Colorectal benign & $16 / 16$ & $16 / 16$ & $1 / 82$ & $74 / 80$ & $30 / 79$ \\
& & & & & \\
Prostate tumour lines & $3 / 4$ & $2 / 5$ & $3 / 5$ & $1 / 5$ & $3 / 4$ \\
Prostate tumours & $3 / 14$ & $1 / 14^{*}$ & $0 / 14$ & $5 / 14$ & $5 / 14$ \\
Prostate benign & $1 / 4$ & $2 / 4^{*}$ & $0 / 4$ & $0 / 4$ & $1 / 4$ \\
\hline
\end{tabular}

Methylation frequencies are shown for lung, colorectal and prostate cancer cell lines and primary tumours and normal tissue. $\left({ }^{*}\right)$ very weak methylation. $D B C 1$ methylation in lung cancer has been demonstrated previously, hence in this study $D B C 1$ was not analysed in lung cancer.

is guided by the expression of estrogen and/or progesterone receptors. Breast cancers that are positive for estrogen receptor and/or progesterone receptor respond better to endocrine therapy compared to receptor negative breast cancers. Our findings indicate that methylation of EMILIN2, CIDE-A and FBLN2 are associated with positive estrogen and or progesterone receptor status, this may help in further refining breast cancers that are more likely to benefit from endocrine therapy.

In our cohort of breast cancer cases, EMILIN2 methylation also correlated with lymph node metastases, relapse and poor survival, hence EMILIN2 methylation is associated with less favourable prognosis. It will be of interest to analyse larger sample numbers to determine if EMILIN2 methylation status can be utilised as a prognostic marker in breast cancer.

\section{Conclusion}

In summary we have identified 5 (EMILIN2, SALL1, $D B C 1, F B L N 2, C I D E-A)$ genes that demonstrated frequent tumour acquired methylation in breast cancer. In addition, EMILIN2 and SALL1 also show frequent methylation in colorectal cancer and FBLN2 shows frequent tumour-specific methylation in prostate cancer. Identification of these methylated genes will help in elucidating the pathology of the affected cancers and in developing epigenetic markers across epithelial and other cancers.

\section{Methods}

\section{Cancer cell lines and patient samples}

Five breast cancer cell lines (HCC1806, HCC1419, HCC1395, HCC1143 and HCC1937) and two normal human mammary epithelial cell lines (NHMEC lines $1585 \mathrm{~T}$ and 3736T) were used for MIRA. CoBRA analysis used an additional four breast cancer cell lines (MCF7, T47D, MDA-MB-231 and HTB19) and one normal breast tissue DNA sample (AMS Biotechnology), replacing the NHMEC lines. Cell lines were grown as described previously $[31,32]$. Clinical and pathological features of the breast cancer cell lines are described in reference 31 and additional file 3. A set of 40 breast tumours (ductal carcinomas) and an independent set of further 20 breast tumours (ductal carcinomas) with corresponding normal breast tissue DNA were analysed. Additional file 4 gives the clinical-pathological
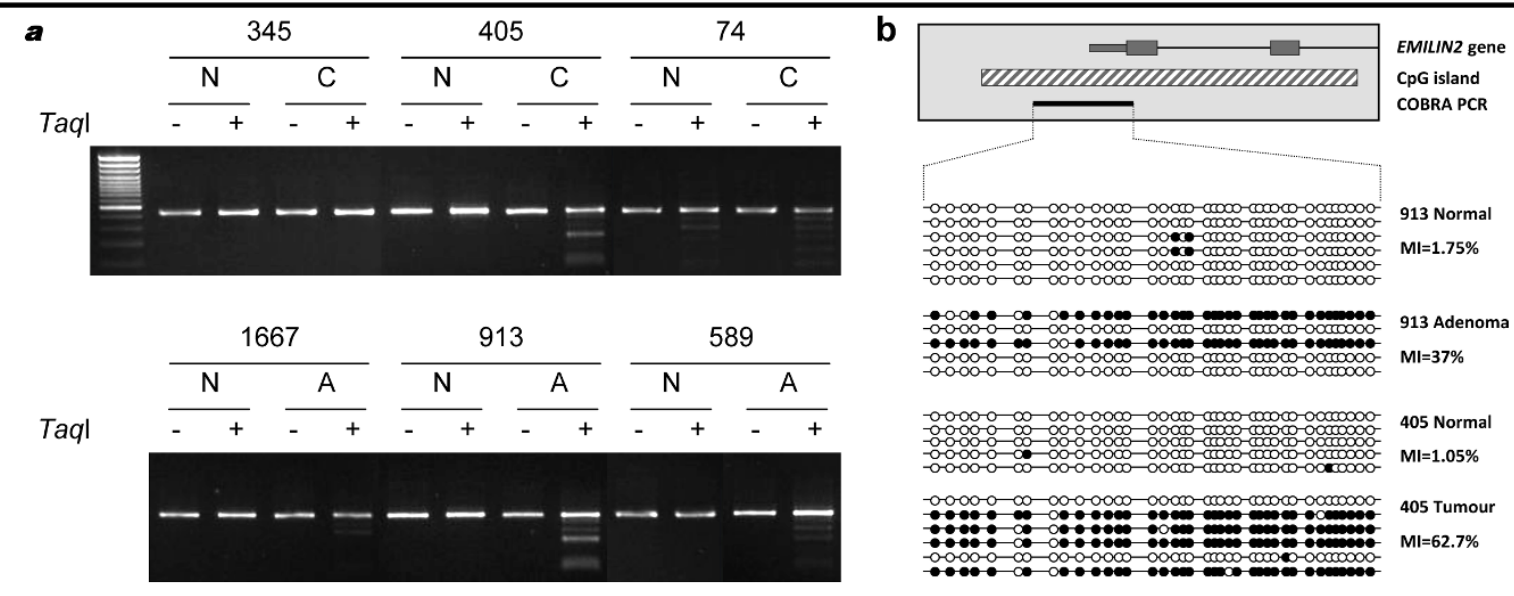

Figure 7 Methylation analysis of EMILIN2 in colorectal cancer. (a) COBRA results are shown with undigested (-) PCR product next to digested (+) PCR product for matching normal $(\mathrm{N})$ and colorectal carcinoma $(\mathrm{C})$ in the upper panel and matching normal $(\mathrm{N})$ and adenoma (A) in the lower panel. (b) Selected PCR products were cloned and sequenced. Individual alleles of each of the four samples shown are represented by a line, black and white circles represent methylated and unmethylated CpG dinucleotides respectively. The frequency of methylation within the amplified region for each sample is indicated by the methylation index (MI). 


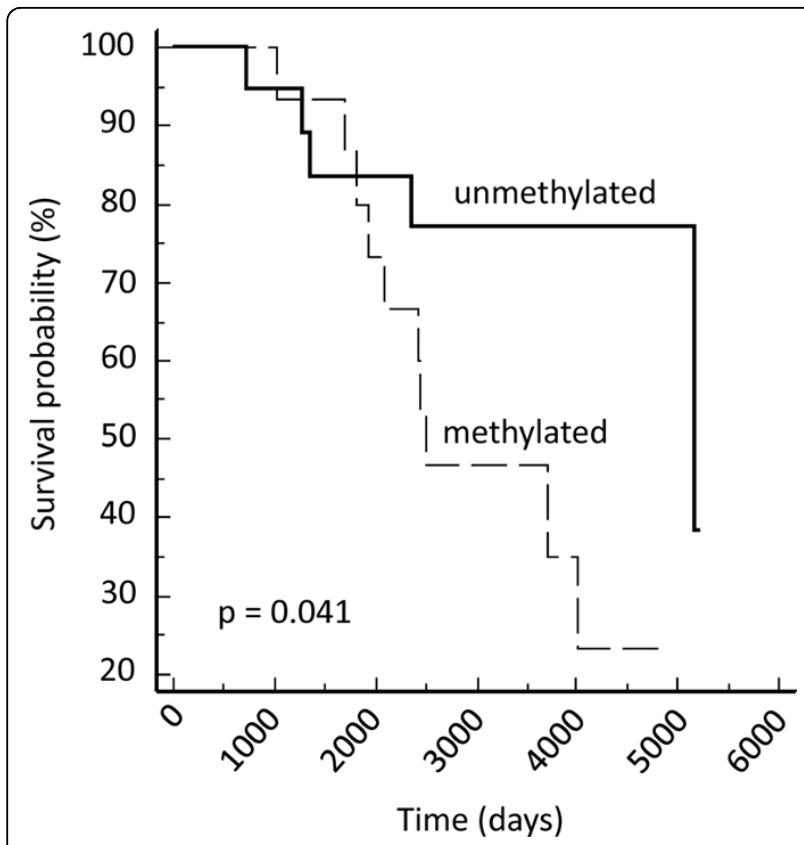

Figure 8 EMILIN2 survival analysis in breast tumours. Kaplan Meier survival analysis for EMILIN2 methylation status and relapse free survival $(P=0.041)$.

information for the breast tumours used in this study. Ethical guidelines were followed for sample collection. A cell line panel consisting of nine colorectal, fifteen lung and five prostate cancer cell lines was used for initial analyses in these cancers. Further work was then carried out using colorectal adenomas and tumours, non small cell lung carcinomas and prostate tumours together with corresponding non cancerous tissue.

\section{MIRA Assay}

The MIRA assay was carried out on five breast cancer cell lines (HCC1806, HCC1419, HCC1395, HCC1143 and HCC1937) and two normal mammary epithelial cell lines (NHMEC lines 1585T and 3736T). The MIRA assay and chip hybridisation procedure was carried out as described previously in references 7 and 8. Human CpG island microarrays containing 27800 CpG islands covering $21 \mathrm{MB}$ were purchased from Agilent Technologies.

\section{Candidate Selection}

Methylation enrichment factors of tumour to normal were calculated for all probes. This data was then analysed as follows:

- First selection, a single probe with a greater than 5-fold increase in MIRA-enriched fraction of tumour versus normal in 3 or more cell lines. This selected for 14,875 probes representing 6,912 individual hits.
- From these hits were removed any that did not represent a known, named gene. This selection removed 145 Open reading frames (Orfs), 3225 Chromosomal regions, 29 miRNAs, 143 Predicted genes (LOCs, MGCs, FLJs and KIAs) and 23 Agilent Plate related hits. This selection retained 3,347 genes $(10,840$ probes $)$ which represent a low stringency candidate list.

- The low stringency candidate probe list was further refined by the removal of all probes not designated to be within promoter or divergent promoter regions. This selection retained 3,352 probes representing 1268 genes.

- Finally, a stricter selection criteria of a single probe with a greater than 10 -fold increase in 4 or more cell lines was applied. This selection retained 895 probes representing 276 genes which represent a high stringency candidate list (see additional file 1)

A large number of target genes were identified using both approaches, particularly the low stringency approach. The low stringency candidate list was compared to a publically available expression array data for an experiment demonstrating the re-expression of genes in the MCF7 breast cancer cell line after treatment with a de-methylating agent (GEO data base accession ID GSE5816). Genes in both the low stringency candidate list and the re-expressed list were then considered. Functional annotation of target genes from both lists was carried out using the functional annotation table function in DAVID http://david.abcc.ncifcrf.gov[33,34]. Additional file 2 shows the results from this analysis for the 32 target genes chosen to be analysed in this study. We also carried out literature searches using Pubmed http://www.ncbi.nlm.nih.gov/pubmed/ for the keywords (breast cancer, Cancer \& Methylation) and searched SAGE expression data(GeneCards-http://www.genecards. org/cgi-bin/cardsearch) and Oncomine https://www. oncomine.org/. UCSC genome browser http://genome. ucsc.edu/ was used to confirm the presence of CpG islands within the likely promoter regions of genes.

\section{Methylation analysis}

Combined bisulphite restriction analysis (CoBRA) was used to analyse all genes in this study. Bisulphite modification of DNA was carried out as described previously [35]. Semi-nested CoBRA primers were designed to amplify specific regions within the $\mathrm{CpG}$ island close to the start of transcription for all 32 genes (primer sequences are shown in additional file 5 for the final 5 positive genes). Digestion of PCR products with BstUI (CGCG) or Taq $\mathrm{I}$ (TCGA) was carried out overnight at $37^{\circ} \mathrm{C}$ or $65^{\circ} \mathrm{C}$ respectively prior to visualisation on a $2 \%$ agarose gel. In vitro methylated DNA was used as a 


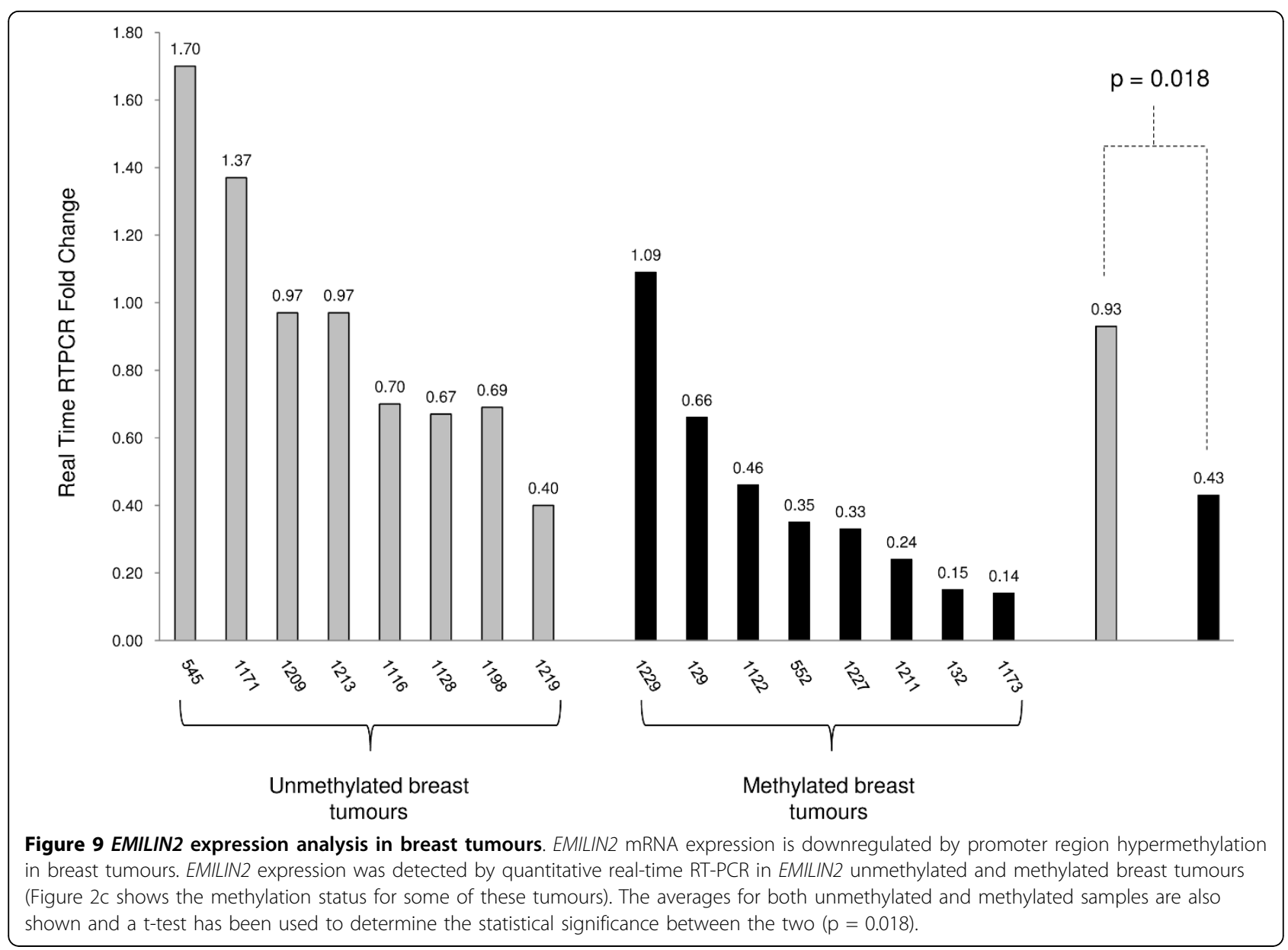

positive control. Confirmation of CoBRA results was obtained by bisulphite sequencing. PCR products from selected samples were cloned into the pGEM-T easy vector (Promega) according to manufacturers' instructions. Single colony PCR was carried out on up to 12 colonies for each cloned sample and methylation index (MI) for each sample calculated as a percentage; number of CpG dinucleotides methylated/total number of $\mathrm{CpG}$ dinucleotides sequenced $\times 100$.

\section{Expression Analysis and 5-aza-2-deoxycitidine treatment} Cell lines were maintained in DMEM media (Sigma Aldrich) supplemented with 10\% FCS and $2 \mathrm{mM}$ glutamine at $37^{\circ}, 5 \% \mathrm{CO}_{2}$. Breast cancer cell lines $\mathrm{HCC} 1806$, HCC1419, HCC1937, HCC1395, MCF7, HTB19, T47D and MDA-MB-231 were treated with $5 \mu \mathrm{M}$ 5-aza-2'deoxycitidine (5-aza-dC). Treatment was carried out over 5 days with daily media changes and addition of fresh 5-aza-dC. RNA bee (AMS biotechnology) was used to extract RNA from 5-aza- $\mathrm{dC}$ treated and non-treated cells. Control breast total RNA was bought from AMS Biotechnology. cDNA was synthesised from $1 \mu \mathrm{g}$ total
RNA using SuperScript III (Invitrogen) and random hexamer primers. Touchdown PCR was used for expression analysis (primer sequences are shown in additional file 6 for the final 5 positive genes). GAPDH analysis was carried out concurrently for each gene using primers and PCR conditions described previously [35]. For each gene we used 2 methylated and one unmethylated cell line for expression analysis.

\section{Real-time RT-PCR}

Quantitative real-time RT-PCR was performed as described previously [36]. Briefly, cDNA was made from total RNA extracted from frozen normal and tumour breast tissues. We quantified transcripts of the TBP (TATA box-binding protein) gene as the endogenous RNA control. Each sample was normalized on the basis of $T B P$ content. Results, expressed as $\mathrm{N}$-fold differences in target gene expression relative to the TBP gene (termed Ntarget), were determined by the following formula: Ntarget $=2 \Delta^{\text {Ctsample }}$, where the $\Delta C t$ value of the sample was determined by subtracting the average $\mathrm{Ct}$ value of the target gene from the average $\mathrm{Ct}$ value of 
the TBP gene. The Ntarget values of the samples were subsequently normalized such that the mean ratio of the normal breast samples would equal a value of 1 . The nucleotide sequences of the primers used for PCR amplification were as follows: (a) EMILIN2-U (5'GCTTGAAGAAAGCCACAGATAATGAA-3') and EMILIN2-L (5'-CTGAGGCCCCTCTTTTGGATCTA-3') with a EMILIN2-specific product size of $116 \mathrm{bp}$, (b) TBP-U (5'-TGCACAGGAGCCAAGAGTGAA-3') and TBP-L (5'-CACATCACAGCTCCCCACCA-3') with a $T B P$-specific product size of $132 \mathrm{bp}$. PCR was performed using the SYBR Green PCR Core Reagents kit (PerkinElmer Applied Biosystems). The thermal cycling conditions comprised an initial denaturation step at $95^{\circ} \mathrm{C}$ for $10 \mathrm{~min}$ and 50 cycles at $95^{\circ} \mathrm{C}$ for $15 \mathrm{~s}$ and $65^{\circ} \mathrm{C}$ for 1 min. Experiments were performed with duplicates for each data point.

\section{Statistical analysis}

Methylation results were summarised using cross-tabulations. Comparisons of methylation rates of genes within the same sample were analysed using McNemar's tests, and exact P-values were obtained. Comparisons of methylation rates between normal and tumour cells were analysed using chi-squared tests. Associations between methylation status and clinicopathological characteristics were assessed using a two-sample t-test for the continuous variable age and chi-squared tests for categorical variables. All analyses were conducted using Stata Version 10.1 (Stata Corporation: College Station, TX, USA).

\section{List of Abbreviations}

MIRA: methylated-CpG island recovery assay; 5-aza-dC: 5-aza-2'deoxycytidine; COBRA: Combined Bisulphite Restriction Analysis; NSCLC: non-small cell lung carcinoma; CRC: colorectal cancer.

Additional file 1: High Stringency Gene List. This file shows all the genes which fulfilled the highest stringency criteria, 1 or more promoter probes scoring greater than 10 in 4 or more cell lines.

Click here for file

[http://www.biomedcentral.com/content/supplementary/1476-4598-9-51S1.XLS ]

Additional file 2: Functional Annotation using the DAVID

Bioinformatics Resource. This file shows the DAVID functional

annotation table for the 32 selected candidate genes http://david.abcc.

ncifcrf.gov/.

Click here for file

[http://www.biomedcentral.com/content/supplementary/1476-4598-9-51S2.XLS]

Additional file 3: Clinical-pathological features of breast cancer cell lines. Table shows the clinical-pathological characteristics of the breast cancer cell lines used in this study.

Click here for file

[http://www.biomedcentral.com/content/supplementary/1476-4598-9-51S3.DOC ]
Additional file 4: Clinical-pathological features of breast tumours.

Table shows the clinical-pathological characteristics of the breast

tumours used in this study.

Click here for file

[ http://www.biomedcentral.com/content/supplementary/1476-4598-9-51S4.DOC]

Additional file 5: Methylation primers. COBRA sequences and annealing temperatures are shown for DBC1, CIDE-A, EMILIN2, FBLN2 and SALL1.

Click here for file

[http://www.biomedcentral.com/content/supplementary/1476-4598-9-51S5.PPTX ]

Additional file 6: Expression primers. Expression primer sequences are shown for DBC1, CIDE-A, EMILIN2, FBLN2 and SALL1.

Click here for file

[http://www.biomedcentral.com/content/supplementary/1476-4598-9-51S6.PPTX ]

\section{Acknowledgements}

F Latif laboratory is partly funded by Breast Cancer Campaign and CRUK. J Minna funded by Komen foundation and DOD. We thank Tapio Visakorpi for providing DNA from prostate tumour cell lines.

\section{Author details}

'Department of Medical and Molecular Genetics, School of Clinical and Experimental Medicine, College of Medical and Dental Sciences, University of Birmingham, Birmingham B15 2TT, UK. ${ }^{2}$ Adult Cancer Program, Lowy Cancer Research Centre and Prince of Wales Clinical School, Faculty of Medicine, University of New South Wales, NSW2052, Australia. Institute for Genetics, Justus Liebig University Giessen, Heinrich-Buff-Ring 58-62, D-35392 Giessen, Germany. ${ }^{4}$ Oncogenetic Laboratory, INSERM U 735, Centre René Huguenin, Saint Cloud, France. ${ }^{5}$ Beckman Research Institute, City of Hope, 1500 E Duarte Road, Duarte, CA 91010. USA. ${ }^{6}$ Department of Surgery, University of Texas Southwestern Medical Center, Dallas, Texas, USA. ${ }^{7}$ Hamon Center for Therapeutic Oncology Research, The University of Texas Southwestern Medical Center at Dallas, Dallas, Texas, USA.

\section{Authors' contributions}

VKH did the experiments involving the breast cancer data (bisulphite modification, COBRA, sequencing, expression and bioinformatics analysis) and analysis of lung, colorectal and prostate cancer cell lines. LBH and RLW carried out analysis in colorectal tumours. T Dansranjavin and RD carried out analysis in prostate tumours. AD did bioinformatics analysis on the MIRA data. IB, DE and $C L$ provided breast tumour DNA samples and NHMEC. IB and SV carried out real-time RT-PCR. ST and GPP performed the MIRA assay and $\mathrm{CpG}$ island array hybridisation. T Dobbins did statistical analysis. DG did tissue culture. JM provided breast tumour cell lines and $N / T$ paired lung DNA samples. ERM contributed to the concept of the study and statistical analysis. FL conceived the studies, oversaw the experimental work, wrote the manuscript and established all the collaborations. All authors have read and approved the final manuscript.

\section{Competing interests}

The authors declare that they have no competing interests.

Received: 24 August 2009

Accepted: 5 March 2010 Published: 5 March 2010

\section{References}

1. Parkin DM, Bray F, Ferlay J, Pisani P: Global cancer statistics. 2002. CA Cancer J Clin 2005, 55:74-108.

2. Chan TA, Glockner S, Yi JM, Chen W, Van Neste L, Cope L, Herman JG, Velculescu V, Schuebel KE, Ahuja N, Baylin SB: Convergence of mutation and epigenetic alterations identifies common genes in cancer that predict for poor prognosis. PLoS Med 2008, 5:e114. 
3. Dworkin AM, Huang TH, Toland AE: Epigenetic alterations in the breast: Implications for breast cancer detection, prognosis and treatment. Semin Cancer Biol 2009, 19:165-171.

4. Widschwendter M, Jones PA: DNA methylation and breast carcinogenesis. Oncogene 2002, 21:5462-5482.

5. Richter AM, Pfeifer GP, Dammann RH: The RASSF proteins in cancer; from epigenetic silencing to functional characterization. Biochim Biophys Acta 2009, 1796:114-128.

6. Hesson LB, Cooper WN, Latif F: The role of RASSF1A methylation in cancer. Dis Markers 2007, 23:73-87.

7. Rauch T, Li H, Wu X, Pfeifer GP: MIRA-assisted microarray analysis, a new technology for the determination of DNA methylation patterns, identifies frequent methylation of homeodomain-containing genes in lung cancer cells. Cancer Res 2006, 66:7939-7947.

8. Rauch T, Wang Z, Zhang X, Zhong X, Wu X, Lau SK, Kernstine KH, Riggs AD, Pfeifer GP: Homeobox gene methylation in lung cancer studied by genome-wide analysis with a microarray-based methylated CpG island recovery assay. Proc Natl Acad Sci USA 2007, 104:5527-5532.

9. Izumi H, Inoue J, Yokoi S, Hosoda H, Shibata T, Sunamori M, Hirohashi S, Inazawa J, Imoto I: Frequent silencing of DBC1 is by genetic or epigenetic mechanisms in non-small cell lung cancers. Hum Mol Genet 2005, 14:997-1007.

10. Li D, Da L, Tang H, Li T, Zhao M: CpG methylation plays a vital role in determining tissue- and cell-specific expression of the human celldeath-inducing DFF45-like effector A gene through the regulation of Sp1/Sp3 binding. Nucleic Acids Res 2008, 36:330-341.

11. Kuang SQ, Tong WG, Yang H, Lin W, Lee MK, Fang ZH, Wei Y, Jelinek J, Issa JP, Garcia-Manero G: Genome-wide identification of aberrantly methylated promoter associated $\mathrm{CpG}$ islands in acute lymphocytic leukemia. Leukemia 2008, 22:1529-1538.

12. Dunwell TL, Hesson LB, Pavlova T, Zabarovska V, Kashuba V, Catchpoole D, Chiaramonte R, Brini AT, Griffiths M, Maher ER, Zabarovsky E, Latif: Epigenetic analysis of childhood acute lymphoblastic leukemia. Epigenetics 2009, 4:185-193.

13. Habuchi T, Takahashi T, Kakinuma H, Wang L, Tsuchiya N, Satoh S, Akao T, Sato K, Ogawa O, Knowles MA, Kato T: Hypermethylation at 9q32-33 tumour suppressor region is age-related in normal urothelium and an early and frequent alteration in bladder cancer. Oncogene 2001, 20:531-537.

14. Gao S, Worm J, Guldberg P, Eiberg H, Krogdahl A, Sørensen JA, Liu CJ, Reibel J, Dabelsteen E: Loss of heterozygosity at $9 q 33$ and hypermethylation of the DBCCR1 gene in oral squamous cell carcinoma. Br J Cancer 2004, 91:760-764.

15. San José-Enériz E, Agirre X, Román-Gómez J, Cordeu L, Garate L, JiménezVelasco A, Vázquez I, Calasanz MJ, Heiniger A, Torres A, Prósper F: Downregulation of DBC1 expression in acute lymphoblastic leukaemia is mediated by aberrant methylation of its promoter. Br J Haematol 2006, 134:137-144.

16. Mongiat M, Ligresti G, Marastoni S, Lorenzon E, Doliana R, Colombatti A: Regulation of the extrinsic apoptotic pathway by the extracellular matrix glycoprotein EMILIN2. Mol Cell Biol 2007, 27:7176-7187.

17. Inohara N, Koseki T, Chen S, Wu X, Núñez G: CIDE, a novel family of cell death activators with homology to the $45 \mathrm{kDa}$ subunit of the DNA fragmentation factor. EMBO J 1998, 17:2526-2533.

18. Zhou Z, Yon Toh S, Chen Z, Guo K, Ng CP, Ponniah S, Lin SC, Hong W, Li P: Cidea-deficient mice have lean phenotype and are resistant to obesity. Nat Genet 2003, 35:49-56

19. Yi CH, Smith DJ, West WW, Hollingsworth MA: Loss of fibulin-2 expression is associated with breast cancer progression. Am J Pathol 2007, 170:1535-1545

20. Sadr-Nabavi A, Ramser J, Volkmann J, Naehrig J, Wiesmann F, Betz B, Hellebrand H, Engert S, Seitz S, Kreutzfeld R, Sasaki T, Arnold N, Schmutzler R, Kiechle M, Niederacher D, Harbeck N, Dahl E, Meindl A: Decreased expression of angiogenesis antagonist EFEMP1 in sporadic breast cancer is caused by aberrant promoter methylation and points to an impact of EFEMP1 as molecular biomarker. Int J Cancer 2009, 124:1727-1735

21. Nishiyama H, Gill JH, Pitt E, Kennedy W, Knowles MA: Negative regulation of $\mathrm{G}(1) / \mathrm{S}$ transition by the candidate bladder tumour suppressor gene DBCCR1. Oncogene 2001, 20:2956-2964.
22. Nishinakamura R, Takasato M: Essential roles of Sall1 in kidney development. Kidney Int 2005, 68:1948-1950.

23. Kohlhase J, Wischermann A, Reichenbach H, Froster U, Engel W: Mutations in the SALL1 putative transcription factor gene cause Townes-Brocks syndrome. Nat Genet 1998, 18:81-83.

24. Argos M, Kibriya MG, Jasmine F, Olopade Ol, Su T, Hibshoosh H, Ahsan H: Genomewide scan for loss of heterozygosity and chromosomal amplification in breast carcinoma using single-nucleotide polymorphism arrays. Cancer Genet Cytogenet 2008, 182:69-74.

25. Chin SF, Wang Y, Thorne NP, Teschendorff AE, Pinder SE, Vias M, Naderi A, Roberts I, Barbosa-Morais NL, Garcia MJ, lyer NG, Kranjac T, Robertson JF, Aparicio S, Tavaré S, Ellis I, Brenton JD, Caldas C: Using array-comparative genomic hybridization to define molecular portraits of primary breast cancers. Oncogene 2007, 26:1959-1970.

26. Kittiniyom K, Gorse KM, Dalbegue F, Lichy JH, Taubenberger JK, Newsham IF: Allelic loss on chromosome band 18p11.3 occurs early and reveals heterogeneity in breast cancer progression. Breast Cancer Res 2001, 3:192-198.

27. Maitra A, Wistuba II, Washington C, Virmani AK, Ashfaq R, Milchgrub S, Gazdar AF, Minna JD: High-resolution chromosome 3p allelotyping of breast carcinomas and precursor lesions demonstrates frequent loss of heterozygosity and a discontinuous pattern of allele loss. Am J Pathol 2001, 159:119-130

28. Braga E, Senchenko V, Bazov I, Loginov W, Liu J, Ermilova V, Kazubskaya T, Garkavtseva R, Mazurenko N, Kisseljov F, Lerman Ml, Klein G, Kisselev L, Zabarovsky ER: Critical tumor-suppressor gene regions on chromosome $3 \mathrm{P}$ in major human epithelial malignancies: allelotyping and quantitative real-time PCR. Int J Cancer 2002, 100:534-541.

29. Karkera JD, Ayache S, Ransome RJ Jr, Jackson MA, Elsayem AF, Sridhar R, Detera-Wadleigh SD, Wadleigh RG: Refinement of regions with allelic loss on chromosome 18p11.2 and 18q12.2 in esophageal squamous cell carcinoma. Clin Cancer Res 2000, 6:3565-3569.

30. Habuchi T, Luscombe M, Elder PA, Knowles MA: Structure and methylation-based silencing of a gene (DBCCR1) within a candidate bladder cancer tumor suppressor region at 9q32-q33. Genomics 1998, 48:277-288.

31. Gazdar AF, Kurvari V, Virmani A, Gollahon L, Sakaguchi M, Westerfield M, Kodagoda D, Stasny V, Cunningham HT, Wistuba II, Tomlinson G, Tonk V, Ashfaq R, Leitch AM, Minna JD, Shay JW: Characterization of paired tumor and non-tumor cell lines established from patients with breast cancer. Int J Cancer 1998, 78:766-774

32. Lewis CM, Herbert BS, Bu D, Halloway S, Beck A, Shadeo A, Zhang C, Ashfaq R, Shay JW, Euhus DM: Telomerase immortalization of human mammary epithelial cells derived from a BRCA2 mutation carrier. Breast Cancer Res Treat 2006, 99:103-115.

33. Huang DW, Sherman BT, Lempicki RA: Systematic and integrative analysis of large gene lists using DAVID Bioinformatics Resources. Nature Protoc 2009, 4(1):44-57.

34. Dennis G Jr, Sherman BT, Hosack DA, Yang J, Gao W, Lane HC, Lempicki RA: DAVID: Database for Annotation, Visualization, and Integrated Discovery. Genome Biol 2003, 4(5):P3.

35. Hesson L, Bieche I, Krex D, Criniere E, Hoang-Xuan K, Maher ER, Latif F: Frequent epigenetic inactivation of RASFIA and BLU genes located within the critical 3p21.3 region in gliomas. Oncogene 2004, 23:2408-2419.

36. Tozlu-Kara S, Roux V, Andrieu C, Vendrell J, Vacher S, Lazar V, Spyratos F, Tubiana-Hulin M, Cohen P, Dessen P, Lidereau R, Bièche I: Oligonucleotide microarray analysis of estrogen receptor alpha-positive postmenopausal breast carcinomas: identification of HRPAP20 and TIMELESS as outstanding candidate markers to predict the response to tamoxifen. $J$ Mol Endocrinol 2007, 39:305-318.

doi:10.1186/1476-4598-9-51

Cite this article as: Hill et al: Identification of 5 novel genes methylated in breast and other epithelial cancers. Molecular Cancer 2010 9:51. 